\title{
Detecção de Listeria, Salmonella e Klebsiella em serviço de alimentação hospitalar
}

\author{
Detection of Listeria, Salmonella and Klebsiella \\ in a hospital food service
}

Uelinton Manoel PINTO'

Rodrigo Rezende CARDOSO'

Maria Cristina Dantas VANETTI ${ }^{1}$

\section{R E S U M O}

\section{Objetivo}

A presença de Listeria monocytogenes, Salmonella sp. e Klebsiella sp. em dietas enterais e em ambientes, utensílios e equipamentos de preparo de alimentos em serviço de alimentação hospitalar, foi o objetivo desta pesquisa.

\section{Métodos}

A contaminação de ambientes, utensílios e equipamentos de preparo de alimentos em serviço de alimentação hospitalar por Listeria monocytogenes, Salmonella sp. e Klebsiella sp. foi avaliada em 50 amostras coletadas pela técnica de swab. Quatro amostras de dietas enterais também foram analisadas. Colônias típicas de bactérias do gênero Listeria foram isoladas de dieta enteral em ágar Oxford e a identificação da espécie $L$. monocytogenes foi feita por testes bioquímicos e imunológicos.

\section{Resultados}

A presença de Salmonella foi detectada em dieta enteral e identificada como S. rissen por sorologia. Pela relevância como agente causador de infecções hospitalares, bactérias do gênero Klebsiella foram pesquisadas e isoladas em ágar seletivo MacConkey-inositol-carbenicilina. K. pneumoniae foi encontrada em equipamento e utensílio e $K$. oxytoca em ambiente, equipamento e dieta enteral. Os isolados de $L$. monocytogenes apresentaram resistência apenas ao antibiótico cefoxitina e os do gênero Klebsiella foram resistentes a ampicilina e amoxilina. S. rissen foi sensível aos 13 antibióticos avaliados.

\footnotetext{
1 Departamento de Microbiologia, Universidade Federal de Viçosa. 36571-000, Viçosa, MG, Brasil. Correspondência para/Correspondence to: M.C.D.VANETTI.E-mail: mvanetti@ufv.br
} 


\section{Conclusão}

A contaminação de $11 \%$ das amostras analisadas com pelo menos um dos patógenos, alerta para a necessidade de implantação de um rigoroso sistema de controle de qualidade nas áreas de manipulação dos alimentos, a fim de aumentar a segurança alimentar dos pacientes hospitalizados.

Termos de indexação: alimentação hospitalar; contaminação bacteriana, patógenos alimentares, susceptibilidade a antibióticos, contaminação de alimentos.

\section{A B S T R A C T}

\section{Objective}

The purpose of the research was to investigate the presence of Listeria, Salmonella and Klebsiella on samples of enteral diets and utensils, surfaces and equipments involved in food preparation in a hospital food service.

\section{Methods}

Fifty samples collected from utensils, surfaces and equipment used for food preparation in a hospital food service, and four samples collected from enteral diets were tested for bacteria of genera Listeria, Salmonella and Klebsiella. Typical colonies of bacteria of the genus Listeria from enteral diet were isolated in Oxford agar and contamination by L. monocytogenes was confirmed by immunoanalysis.

\section{Results}

L. monocytogenes, S. rissen and Klebsiella were isolated from enteral diet. For their relevance as agents of hospital infections, bacteria of the genus Klebsiella were evaluated. K. pneumoniae were found in equipment and utensil, and K. oxytoca were found in environment, equipment and enteral diet samples. L. monocytogenes showed resistance to cefoxitin and all Klebsiella were resistant to amoxacillin and ampicillin. S. rissen showed susceptibility to all 13 antibiotics tested.

\section{Conclusion}

The study showed that $11 \%$ of the analyzed samples were contaminated with, at least, one of the investigated pathogens. Such results reiterate the need for awareness and knowledge of effective hygienic procedures in the hospital food manipulation areas, in order to ensure patients' safety.

Index terms: food service; bacterial contamination, foodborne pathogens; antibiotic susceptibility, food contamination.

\section{N T R O D U Ç Ã O}

Registros epidemiológicos revelam que a maioria dos surtos de doenças de origem alimentar é causada por alimentos preparados em serviços de alimentação'. Tais surtos decorrem, principalmente, da contaminação de alimentos por bactérias como: Staphylococcus aureus, Clostridium perfringens, Salmonella sp., Yersinia enterocolitica, Escherichia coli e Shigella sp., dentre outras. O controle da contaminação dos alimentos por microorganismos deterioradores e patogênicos nas operações de serviços de alimentação é difícil e complexo devido à grande variedade de alimentos preparados e à necessidade da rápida utilização dos mesmos, não havendo tempo para análises. Há também o risco potencial de os manipuladores de alimentos se constituirem em portadores sadios de microorganismos patogênicos. 
As infecções alimentares são particularmente importantes quando ocorrem em pacientes hospitalizados, idosos ou imunocomprometidos ${ }^{2}$. Aproximadamente $50 \%$ das infecções que acometem pacientes hospitalizados são causadas por microorganismos hospitalares que colonizam o trato gastrintestinal ${ }^{3}$. Apesar disso, pouca importância é dada aos alimentos como fonte de microorganismos capazes de causar infecções hospitalares. Dietas enterais e formulados infantis devem receber atenção especial, considerando que os pacientes a quem são destinados são, geralmente, mais susceptíveis a infecções, a desidratações e suas conseqüências.

Bactérias enteropatogênicas como Salmonella sp., Shigella sp., E. coli e Campylobacter são isoladas freqüentemente em infecções ocorridas em enfermarias e pediatrias de unidades hospitalares ${ }^{4,5}$. Constata-se que, pacientes hospitalizados ou indivíduos cujas defesas foram enfraquecidas por doenças ou terapias, estão susceptíveis às infecções causadas não só pelas bactérias reconhecidas como patogênicas de origem alimentar, como também por outros microorganismos que, geralmente, não acometem pessoas saudáveis. Entre esses patógenos oportunistas veiculados por alimentos destacam-se bactérias Gram-negativas como Enterobacter sakazakií; Citrobacter freudii?; Pseudomonas aeruginosa ${ }^{8}$ e Klebsiella sp ${ }^{9}$. Além de serem oportunistas, alguns microorganismos envolvidos em infecções nosocomiais tornam-se resistentes às drogas antimicrobianas comumente usadas nos ambientes hospitalares. A emergência de patógenos resistentes a antibióticos é um fenômeno de preocupação na área clínica e na farmacêutica pois, segundo Meng \& Doyle ${ }^{2}$, sua resistência pode comprometer o tratamento de infecções alimentares severas.

Considerando que os alimentos podem constituir fonte potencial de patógenos no ambiente hospitalar, o objetivo do presente trabalho foi avaliar a presença de Listeria, Salmonella e Klebsiella em um serviço de alimentação hospitalar e determinar o perfil de resistência a antibióticos das bactérias isoladas.

\section{MATERIAIS E MÉTODOS}

Cinqüenta amostras obtidas de ambientes, superfícies, utensílios e equipamentos de uma cozinha e um lactário hospitalar, foram coletadas em seis visitas diferentes, realizadas no período da manhã, após o preparo das refeições e sanitização dos equipamentos, superfícies e utensílios. As amostras foram coletadas aleatoriamente, totalizando 27 utensílios como panelas, copos, colheres, bandejas, coador, mamadeiras e potes plásticos; as amostras de superfícies incluíram três de bancadas e três de pias; as de ambientes, incluíram três amostras de ralos, quatro de torneiras e uma de azulejos. As amostras de equipamentos compreenderam três de batedeiras e seis de liqüidificadores. A técnica do swab foi empregada para a coleta de amostras. Tubos com $7 \mathrm{~cm}$ a $10 \mathrm{~cm}$ de comprimento foram preparados com $10 \mathrm{~mL}$ de caldo Universidade de Vermont Modificado (UVM) (Oxoid, Basingstoke, Hampshire) para isolamento de Listeria e com $10 \mathrm{~mL}$ de água peptonada tamponada $1 \%$ para o isolamento de Salmonella e Klebsiella. Em utensílios e equipamentos, a amostragem correspondeu à área total, percorrida com swab por três vezes consecutivas. Para a amostragem de superfícies de processamento, utilizou-se o swab embebido em caldo UVM ou em água peptonada tamponada $1 \%$, aplicado a um ângulo de $30^{\circ}$ de contato com a superfície, percorrendo cinco áreas de $50 \mathrm{~cm}^{2}$, por três vezes consecutivas. Após a coleta do material, cada swab teve a parte manuseada cortada e descartada, e foi colocado no tubo apropriado contendo o meio de cultura.

Também foram coletadas em frascos plásticos, quatro amostras de dietas enterais modulares com volumes aproximados de $100 \mathrm{~mL}$, a seguir encaminhadas ao laboratório, sob refrigeração, para a análise microbiológica. 


\section{Isolamento e identificação das bactérias}

\section{Listeria monocytogenes}

Os swabs com amostras coletadas dos utensílios e equipamentos, destinados à detecção de Listeria, foram incubados em caldo de enriquecimento primário UVM a $30^{\circ} \mathrm{C}$ por $26 \mathrm{~h}$; após este período, uma alíquota de $1 \mathrm{~mL}$ foi transferida para $10 \mathrm{~mL}$ de caldo Fraser (Oxoid) para enriquecimento secundário. Após a incubação a $35^{\circ} \mathrm{C}$ por $30 \mathrm{~h}$, as amostras foram semeadas, pelo método de estria composta, em ágar seletivo Oxford (Oxoid) por $48 \mathrm{~h}$ a $35^{\circ} \mathrm{C}$. De cada placa de ágar Oxford com colônias suspeitas de Listeria, caracterizadas por apresentarem-se pretas, com halo escuro resultante da degradação da esculina, três colônias foram selecionadas e estriadas em ágar tripticaseína e soja-TSA (Oxoid) adicionado de $0,6 \%$ de extrato de levedura. As colônias isoladas foram mantidas em ágar semi-sólido SIM - Sulfito-indol-motilidade (Difco, Detroit, Michigan) sob refrigeração a, aproximadamente, $4^{\circ} \mathrm{C}$.

A análise de Listeria em dietas enterais foi feita em amostras de $25 \mathrm{~g}$ acrescentadas de $225 \mathrm{~mL}$ de caldo LEB (Difco) com suplemento seletivo SRE 142E (Oxoid) e homogeneizadas em stomacher por 2 minutos. O homogenato foi incubado a $30^{\circ} \mathrm{C}$ por $26 \mathrm{~h}$ e uma alíquota de $0,2 \mathrm{~mL}$ foi transferida para caldo Fraser, para enriquecimento secundário. Após incubação por mais $30 \mathrm{~h} \mathrm{a} 35^{\circ} \mathrm{C}$, a verificação de colônias suspeitas de Listeria foi feita em ágar Oxford. Em todas as amostras coletadas, foi realizada, simultaneamente, a detecção de Listeria em imunoanalisador automático (Mini-Vidas, BioLab BioMérieux) em alíquotas de $500 \mu \mathrm{L}$ do caldo de enriquecimento secundário.

A confirmação do gênero Listeria foi feita por meio de teste de Gram e teste de motilidade em ágar semi-sólido SIM com incubação a $25^{\circ} \mathrm{C}$ por $48 \mathrm{~h}$ a $72 \mathrm{~h}$. A caracterização bioquímica dos isolados constou dos testes de fermentação de xilose, ramnose e manitol, da avaliação da atividade de $\beta$-hemólise e do teste CAMP, feitos em meio base para ágar sangue (Oxoid) suplementado com $5 \%$ de sangue de carneiro desfibrinizado ${ }^{10}$. Utilizaram-se culturas de $S$. aureus ATCC 25923 e Rhodococcus equi ATCC 33701 para o teste CAMP.

\section{Salmonella sp.}

Os swabs com as amostras coletadas dos utensílios e equipamentos destinados à detecção de Salmonella, foram incubados em água peptonada tamponada $1 \%$ a $37^{\circ} \mathrm{C}$ por $18 \mathrm{~h}$; após este período, alíquotas de $1 \mathrm{~mL}$ foram transferidas para caldo Rappaport-Vassiliardis (RP) e caldo Selenito-Cistina (SC) para o enriquecimento seletivo, sendo incubados a $42^{\circ} \mathrm{C}$ e $37^{\circ} \mathrm{C}$, respectivamente, por 24 horas $^{10}$. De cada tubo, procedeu-se o isolamento de colônias típicas em ágar XLD e BPLS (Merck, Darmstsdt, Alemanha) por meio de estria composta com incubação por $24 \mathrm{~h}$ a $37^{\circ} \mathrm{C}$. Colônias suspeitas foram estriadas em ágar inclinado TSI e LIA (Merck), seguindo-se de incubação por $24 \mathrm{~h}$ a $37^{\circ} \mathrm{C}$. Os isolados que apresentaram reações características de Salmonella sp. foram submetidos à identificação bioquímica com os seguintes testes: produção de urease, motilidade em meio SIM, produção de $\mathrm{H}_{2} \mathrm{~S}$, utilização de citrato, produção de indol, fermentação do malonato e produção de fenilalanina. Os isolados que apresentaram resultado característico para Salmonella sp. nos testes bioquímicos foram avaliados por teste sorológico, com antisoro polivalente (antígeno $\mathrm{O}$, Difco). A confirmação das colônias suspeitas de serem Salmonella sp. também foi feita em imunoanalisador MiniVidas (Biolab BioMerieux) a partir dos caldos de enriquecimento; a sorotipagem para reconhecimento da espécie foi conduzida no Laboratório de Zoonoses Bacterianas da Fundação Oswaldo Cruz, RJ.

\section{Klebsiella sp.}

Das amostras coletadas com swabs e das provenientes das dietas enterais foi feito o isolamento de Klebsiella, em meio seletivo 
MacConkey-inositol-carbenicilina (Merck) ${ }^{11}$. Três a cinco colônias típicas de Klebsiella de cada amostra foram estriadas em ágar tripticaseina e soja-TSA (Oxoid) e mantidas em meio Infusão Cérebro e Coração-BHI (Oxoid) semi-sólido a $4^{\circ} \mathrm{C}$.

A identificação dos isolados foi feita por testes morfo-tintoriais e pelo sistema de identificação de bactérias Gram-negativas API 20E (API, LA Balme Les Grottes, França).

\section{Susceptibilidade a antibióticos}

A susceptibilidade dos isolados de Salmonella e Klebsiella aos agentes antimicrobianos foi determinada pelo método de disco-difusão em ágar Mueller-Hinton (Oxoid), enquanto os isolados de Listeria foram avaliados em ágar TSA + 0,6\% de extrato de levedura. Para Klebsiella e Salmonella, os antibióticos usados (Sensibiodisc-CECON, São Paulo, Brasil) foram: ácido nalidíxico-NAL $(30 \mu \mathrm{g})$, amicacina-AMI $(30 \mu \mathrm{g})$, amoxicilina-AMO $(10 \mu \mathrm{g})$, amoxicilina + ácido clavulânico-AMC $(30 \mu \mathrm{g} / 10 \mu \mathrm{g})$, ampicilina-AMP $(10 \mu \mathrm{g})$, cloranfenicol-CLO $(30 \mu \mathrm{g})$, gentamicina-GEN $(10 \mu \mathrm{g})$, imipenem-IMP $(30 \mu \mathrm{g})$, kanamicina-KN $(30 \mu \mathrm{g})$, neomicina-NO $(30 \mu \mathrm{g})$, tetraciclina-TET $(30 \mu \mathrm{g})$, ticarcilina + ácido clavulânico-TIC $(75 \mu \mathrm{g} / 10 \mu \mathrm{g})$ e trimetropim e sulfametoxazol-SUT $(1,25 / 23,75 \mu \mathrm{g})$. Para Listeria, os antibióticos usados foram: amicacina $(30 \mu \mathrm{g})$, ampicilina $(10 \mu \mathrm{g})$, cefalotina $(30 \mu \mathrm{g})$, cefotaxima $(30 \mathrm{mg})$, cefoxitina $(30 \mu \mathrm{g})$, cloranfenicol $(30 \mu \mathrm{g})$, eritromicina $(15 \mu \mathrm{g})$, gentamicina $(10 \mu \mathrm{g})$, kanamicina $(30 \mu \mathrm{g})$, tetraciclina $(30 \mu \mathrm{g})$ e tobramicina $(10 \mu \mathrm{g})$.

\section{RES U LTA DOS}

A análise das 50 amostras, distribuídas entre as amostras ambientais, as de equipamentos, de superfícies e as quatro amostras de dietas enterais, resultou no isolamento de três colônias típicas de bactérias do gênero Listeria, cinco do gênero Salmonella e oito do gênero Klebsiella. Os resultados da identificação bioquímica evidenciaram que seis amostras (11\%) apresentavam-se contaminadas com, pelo menos uma das bactérias analisadas (Tabela 1).

A presença de colônias típicas do gênero Listeria na amostra de dieta enteral foi detectada ao utilizar-se a técnica convencional, que compreende o enriquecimento primário, secundário e isolamento em meio seletivo e ao avaliar-se a mesma amostra em imunoanalisador MiniVidas. Os testes bioquímicos conduzidos identificaram os isolados como pertencentes à espécie $L$. monocytogenes.

Salmonella também foi isolada em amostra de dieta enteral (Tabela 1) tanto pelo procedimento convencional como pelo teste imunoanalítico. A identificação sorológica conduzida na Fundação Osvaldo Cruz (FIOCRUZ) indicou tratar-se de Salmonella rissen 6767 Fg monoflagelar.

Tabela 1. Amostras de equipamentos, utensílios, ambiente e dietas enterais contaminadas com bactérias patogênicas ou potencialmente patogênicas.

\begin{tabular}{lcccc}
\hline Amostras & L. monocytogenes & Salmonella & K. pneumoniae & K. oxytoca \\
\hline Dieta enteral 1 & + & - & - & - \\
Dieta enteral 2 & - & + & - & + \\
Liquidificador 1 & - & - & - & + \\
Liquidificador 2 & - & - & - & - \\
Utensílio 1 $1^{\text {a }}$ & - & - & - & + \\
Ambiente $^{\text {b }}$ & - & - & + \\
\hline
\end{tabular}

(a) Amostragem feita em colher de madeira; (b) Amostragem de uma torneira na cozinha. 
Dos oito isolados suspeitos de serem Klebsiella sp, selecionados pela morfologia típica da colônia em ágar MacConkey-carbenicilina-inositol, a identificação bioquímica reconheceu apenas dois como pertencentes à espécie $K$. pneumoniae e três à espécie $K$. oxytoca. Os demais isolados não foram conclusivamente identificados.

Os isolados de L. monocytogenes avaliados apresentaram resistência intermediária apenas ao antibiótico cefoxitina, e sensibilidade aos demais antibióticos avaliados. Constatou-se também uma elevada sensibilidade dos isolados de Salmonella e de Klebsiella aos antibióticos testados, embora os isolados de Klebsiella apresentassem resistência à ampicilina e à amoxilina.

\section{I S C U S S Ã O}

A presença de patógenos verificada nos ambientes, utensílios e equipamentos de processamento do serviço de alimentação hospitalar, alerta para o risco da contaminação cruzada dos alimentos que podem veicular tais patógenos para os pacientes. Além disso, os resultados indicam que as práticas de limpeza e sanitização não estão sendo suficientes para eliminar tais patógenos. Lisboa $^{12}$ constatou uma grande variação na contaminação de manipuladores, utensílios e superfícies de processamento de alimentos por bactérias Gram-negativas em ambiente de cozinha hospitalar, onde cerca de $80 \%$ dos contaminantes pertenciam à família Enterobacteriaceae, incluindo Salmonella sp., Escherichia coli, Shigella sp. e Yersinia enterocolitica. Sammarco et al..$^{13}$ relataram que se faz necessária a aplicação de sanitizantes mais potentes e adoção de boas práticas de higiene para prevenir a contaminação com $L$. monocytogenes, Salmonella sp. e Y. enterocolitica em unidades industriais de processamento de carne. Sugere-se que tais práticas sejam estendidas à cozinha hospitalar.

K. pneumoniae foi isolada de uma colher de madeira, utensílio não recomendado para o preparo de alimentação, devido à sua alta porosidade, que dificulta a higienização e favorece o crescimento microbiano.

A presença de L. monocytogenes e de Salmonella sp. em dietas enterais pode ser resultante de contaminação cruzada e desperta uma grande preocupação quanto à saúde dos pacientes. L. monocytogenes é um patógeno de risco para pessoas imunodeprimidas, um quadro geralmente presente em pessoas que recebem esse tipo de dieta. A ocorrência de $L$. monocytogenes e de Salmonella sp. em dietas enterais classifica esse alimento como impróprio para consumo de acordo com o Regulamento Técnico que fixa os requisitos mínimos exigidos para terapia de nutrição enteral estabelecidos na $\mathrm{RDC} \mathrm{n}^{\circ} 63$ de 6 de julho de $2000^{14}$. Dietas enterais constituem um substrato para crescimento rápido de bactérias e, nas condições geralmente adotadas de tempo e temperatura de administração, Salmonella sp. pode apresentar um tempo de geração entre 24 e 34 minutos $^{15}$, alcançando números elevados, mesmo que a contaminação inicial tenha sido baixa.

Uma observação importante foi que as dietas enterais contaminadas com $L$. monocytogenes ou com Salmonella sp. foram aquelas submetidas a uma maior manipulação, pois continham maior número de ingredientes para mistura e homogeneização. Nessa situação, a contaminação pode ser atribuída tanto aos ingredientes utilizados quanto às práticas inadequadas de manipulação. Segundo Freedland et al. ${ }^{16}$, uma taxa de 30\% a 90\% de contaminação em sistemas de alimentação enteral está normalmente associada à falta de atenção dos manipuladores para com as técnicas de higiene adequadas, à inabilidade para sanitizar equipamentos de preparação e aos ingredientes aditivos não estéreis ou contaminados adicionados às dietas.

Estes resultados alertam para a necessidade de implantação de um sistema de controle microbiológico na área de manipulação de alimentos, controle que deve ser estendido aos 
funcionários envolvidos nesse processo. O sistema APPCC - Análise de Perigos e Pontos Críticos de Controle - tem por objetivos identificar e prevenir situações, locais ou ações em que estejam presentes perigos de contaminação de alimentos por patógenos. Trata-se de uma ferramenta indispensável no processo de garantia de higiene de alimentos, especialmente dos destinados a grupos de risco. De acordo com Oliveira et al. ${ }^{17}$, a implantação do sistema APPCC durante a preparação, estocagem, distribuição e entrega das dietas aos pacientes resulta em uma melhora significativa da qualidade microbiológica das mesmas. Juntamente com a implementação do sistema APPCC, um treinamento do pessoal envolvido no que diz respeito à lavagem correta das mãos, práticas de higiene, limpeza e desinfecção de recipientes e materiais que entram em contato com as dietas, controle de temperatura adequado e roupas adequadas com protetores têm reduzido o risco de contaminação de dietas reconstituídas. Almeida et al. ${ }^{18}$ destacaram a implantação do APPCC, como uma estratégia para melhorar a qualidade de fórmulas infantis preparadas em hospitais; como resultado, verificaram uma redução significativa na contaminação de utensílios e mãos de manipuladores de alimentos. A adoção desse sistema nos setores de alimentação dos hospitais certamente irá trazer grandes melhorias na qualidade e inocuidade dos alimentos e dietas preparados nesses locais.

A sensibilidade dos isolados à maioria dos antibióticos avaliados difere da expectativa de que a microbiota contaminante de alimentos, manipuladores, ambientes e utensílios em cozinhas hospitalares geralmente apresenta um perfil de maior resistência a antibióticos do que a microbiota de outros ambientes de preparo de alimentos $^{19}$. Resultados de Lisboa ${ }^{12}$ mostraram que Salmonella sp. presente em ambientes de preparo de alimentos em hospital apresentaram-se resistentes a cloranfenicol e tetraciclina, enquanto os isolados de Klebsiella sp. foram resistentes a ampicilina, kanamicina e tetraciclina. Na maioria dos isolados resistentes aos antibióticos (78\%), esse autor constatou a presença de DNA plasmidial que pode conter genes responsáveis pela resistência a um ou mais antibióticos e que podem ser disseminados intra e interespécies bacterianas, contribuindo para o insucesso das terapias antimicrobianas. Perfil de resistência semelhante ao encontrado no presente estudo, foi registrado por Pereira ${ }^{11}$ num estudo em que todos os 21 isolados de Klebsiella sp. de dietas enterais foram resistentes aos antibióticos amoxicilina e ampicilina.

A resistência de $L$. monocytogenes isolada da dieta enteral ao antibiótico cefoxitina também foi encontrada em isolados de $L$. monocytogenes provenientes de carne e leite ${ }^{20}$. Os autores desses estudos verificaram também nos isolados um índice elevado de resistência a cefotaxima, amicacina, cloranfenicol, tetraciclina, eritromicina, tobramicina, gentamicina, cefalotina e ampicilina.

\section{O N C L USÃ O}

Os dados obtidos alertam para a necessidade de implantação de um rigoroso sistema de controle de qualidade microbiológica nas áreas de manipulação dos alimentos e das dietas enterais, incluindo as boas práticas de fabricação e APPCC.

\section{A GRADECIMENTOS}

À FAPEMIG, pelo apoio financeiro e bolsa de Iniciação Científica. À FIOCRUZ na pessoa do Dr. Ernesto Hofer e Dra. Eliane Moura Flavina dos Reis, pela sorotipagem do isolado de Salmonella.

\section{REFER Ê N CIAS}

1. Bryan FL. Hazard Analysis Critical Control Point - HACCP: systems for retail food and restaurant operation. J Food Prot 1990; 53(11):978-83.

2. Meng J, Doyle M. Introduction: microbial food safety. Microbes Infect 2002; 4(4):395-7. 
3. Schooter RA, Faiers MC, Cooke EM, Breaden AL, O'Farrell SM. Isolation of Escherichia coli, Pseudomonas aeruginosa and Klebsiella from food in hospital, canteens and schools. Lancet 1971; 2:390-2.

4. Pessoa GNA. Ocorrência de bactérias enteropatogênicas em São Paulo no septênio 1970-1976. III-Sorotipos de Shigella e de Escherichia coli da gastroenterite infantil. Rev Inst Adolfo Lutz 1978; 38:129-39.

5. Youssef $M$, Shurman A, Bougnoux ME, Rawasheded M, Bretagne S, Strockbine N. Bacterial, viral and parasitic enteric pathogens associated with acute diarrhea in hospitalized children from northen Jordan. FEMS Immun Med Microbiol 2000; 28(3):257-63.

6. Simmons BP, Gelfand MS, Hass M, Mets L, Ferguson J. Enterobacter sakazakii infections in neonates associated with intrinsic contamination of powdered infant formula. Infect Control Hosp Epidemiol 1989; 10(10):398-401.

7. Thurm V, Gericke B. Identification of infant food as a vehicle in a nosocomial outbreak of Citrobacter freundii: epidemiological subtyping by allozime, whole-sell protein and antibiotic resistance. J Appl Bacteriol 1994; 76(4):553-8.

8. File TM, Tan JS, Thomson Jr RBRB, Stephens C, Thompson P. An outbreak of Pseudomonas aeruginosa ventilator - associated respiratory infection due to contaminated food coloring dye-further evidence of the significance of gastric colonization preceding nosocomial infection. Infect Control Hosp Epidemiol 1995; 16(7): 417-8.

9. Anathan S, Ray S, Alvandi S. Enterotoxigenicity of Klebsiella pneumoniae associated with childhood gastroenteretis in Madras, India. Jpn J Infect Dis 1999; 52:16-7.

10. Vanderzant C, Splittstoesser F. Compendium of methods for the microbiological examination of foods. 3rd ed. Washington, DC: APHA; 1992. p.51-74.

11. Pereira SCL. Caracterização molecular e de fatores de virulência de Klebsiella ssp. isoladas de dietas enterais [dissertação]. Viçosa: Universidade Federal de Viçosa; 2001.

12. Lisboa SC. Bactérias Gram negativas e Staphylococcus aureus em serviço de alimentação hospitalar [dissertação]. Viçosa: Universidade Federal de Viçosa; 1997.

13. Sammarco ML, Ripabelli G, Ruberto A, lannitto G, Grasso GM. Prevalence of Salmonella, Listeriae, and Yersiniae in the slaughterhouse environment and on work surfaces, equipment and workers. J Food Prot 1997; 60(4):367-71.

14. Ministério da Saúde (Brasil). Resolução - RDC $n^{\circ}$ 63, de 6 de julho de 2000: aprova Regulamento Técnico para fixar os requisitos mínimos exigidos para terapia de nutrição enteral. Brasília: Diário Oficial da União da República Federativa do Brasil; 2000.

15. Silva RR. Crescimento de Salmonella enteritidis var. Typhimurium em dietas enterais [dissertação]. Viçosa: Universidade Federal de Viçosa; 2000.

16. Freedland CP, Roller RD, Flynm NM. Microbial contamination of continuous drip feedings. J Parent Ent Nut 1989; 13:18.

17. Oliveira MH, Bonelli R, Aidoo KE, Batista RV. Microbiological quality of reconstituted enteral formulations used in hospitals. Nutrition 2000; 16(9):729-33

18. Almeida RCC, Matos CO, Almeida PF. Implementation of a HACCP system for on-site hospital preparation of infant formula. Food Control 1999; 10:181-7.

19. Ostroff SM. Emerging infectious diseases in the institutional setting: another hot zone. Infect Control Hosp Epidemiol 1996; 17(8):484-9.

20. Rota C, Yangüela J, Blanco D, Carramiñana JJ, Ariño A, Herrera A. High prevalence of multiple resistance to antibiotics in 144 Listeria isolates from Spanish dairy and meat products. J Food Prot 1996; 11:938-43.

Recebido para publicação em 2 de setembro de 2002 e aceito em 8 de agosto de 2003. 